Ambiente \& Água - An Interdisciplinary Journal of Applied Science
ISSN 1980-993X - doi:10.4136/1980-993X
www.ambi-agua.net
E-mail: ambi.agua@gmail.com

\title{
As águas minerais no Brasil: uma análise do mercado e da institucionalidade para uma gestão integrada e sustentável
}

\author{
doi: 10.4136/ambi-agua.1357
}

Received: 04 Apr. 2014; Accepted: 02 Mar. 2015

\author{
Pedro dos Santos Portugal Júnior ${ }^{1 *}$; Bastiaan Philip Reydon ${ }^{2}$; \\ Nilton dos Santos Portugal ${ }^{1}$ \\ ${ }^{1}$ Centro Universitário do Sul de Minas (UNIS-MG), Varginha, MG, Brasil \\ ${ }^{2}$ Universidade Estadual de Campinas (Unicamp), Campinas, SP, Brasil \\ Núcleo de Economia Agrícola, Agrária e do Meio Ambiente \\ *Autor correspondente: e-mail: pedrorotaract@hotmail.com, \\ basrey@eco.unicamp.br, nilton@unis.edu.br
}

\section{RESUMO}

O presente artigo visa apresentar uma análise geral do mercado de águas minerais no Brasil, envolvendo para isso três considerações importantes: primeiramente analisa-se a estrutura de mercado predominante neste segmento, abordando-se a evolução e principais grupos que compõem o mercado brasileiro de águas minerais; posteriormente faz-se uma breve referência ao quadro legal e institucional sobre as águas minerais; e por fim, analisam-se direcionamentos para uma gestão ambiental integrada e sustentável nesse segmento. Busca-se, dessa maneira, contextualizar o mercado estudado nos parâmetros legais, institucionais e econômicos, bem como, suas principais implicações que podem ser decisivas no processo de gestão ambiental a ser utilizado pelas empresas, enfatizando a importância de mudanças em suas institucionalidades para uma maior excelência nesse processo. Tais mudanças passam pela consideração da água mineral como recurso hídrico, incluída na Política Nacional de Recursos Hídricos (PNRH), e não mais como um minério. Bem como, incluir também na Política Nacional de Resíduos Sólidos (PNRS), com uma visão completa do ciclo de vida do produto.

Palavras-chave: arranjos institucionais, recursos hídricos, sustentabilidade ambiental.

\section{Mineral waters in Brazil: an analysis of the market and institutional framework for integrated and sustainable management}

\begin{abstract}
This article presents an overview of the mineral water market in Brazil, based on three important considerations: first, the market structure prevailing in this segment is analyzed, addressing the evolution and main groups that make up the Brazilian market for mineral waters; next, we make a brief reference to the legal and institutional framework on mineral waters; and finally, we analyze the directions for integrated and sustainable environmental management in this segment. In this way, we sought to contextualize the market's legal, institutional and economic parameters, as well as the implications of these parameters that can be decisive in the environmental management process, which companies can use to enhance
\end{abstract}


the excellence of that process. These changes imply that mineral water be included in the national policy of water resources, named the PNRH, and not as an ore. It should also be included in the National Plan of Solid Waste (PNRS), with a complete view of the product life cycle.

Keywords: environmental sustainability, institutional arrangements, water resources.

\section{INTRODUÇÃO}

A sustentabilidade ambiental vem se colocando no debate público e nos mais variados fóruns de decisões públicas e privadas, como requisito para a utilização correta dos recursos naturais, respeitando a capacidade de suporte dos ecossistemas e sua regeneração. Integrar esse requisito maior no âmbito das tomadas de decisão nos domínios político, social e empresarial tem colocado desafios não negligenciáveis a construção de novas institucionalidades, ou reformulação das institucionalidades vigentes, no intuito de aperfeiçoar a gestão e a governança dos recursos naturais.

No caso da gestão de recursos hídricos - ou da governança da água - essa reconstrução institucional ganha contornos específicos e um caráter de urgência, principalmente em virtude da sua iminente escassez relativa e absoluta. Essa escassez, já é percebida atualmente em muitas partes do planeta, e tende a se aprofundar e a se estender.

De acordo com estudo das Nações Unidas (2014) atualmente cerca de 1,2 bilhão de pessoas vivem em áreas de escassez física de água. Até 2015 as previsões desse estudo indicam que 1,8 bilhão de pessoas viverão em países ou regiões com escassez absoluta de água. Tal fato poderá provocar deslocamentos de grandes contingentes populacionais em busca desse recurso, emergindo assim os "refugiados ambientais".

O Brasil aparentemente apresenta uma situação até certo ponto confortável em função de sua elevada disponibilidade hídrica per capta. No entanto, conforme a Agência Nacional de Águas (ANA, 2013), o país possui uma distribuição desigual dos recursos hídricos, sendo que $80 \%$ da disponibilidade hídrica concentram-se na Região Hidrográfica Amazônica que tem o menor contingente populacional. Nas regiões mais povoadas já ocorrem situações graves como, por exemplo: I) nos rios da região Nordeste onde há criticidade quantitativa dada a baixa disponibilidade hídrica para atender a demanda; II) na região Sul pela alta demanda para irrigação; e III) nas regiões metropolitanas do Sul e Sudeste que apresentam criticidade quali-quantitativa, tendo em vista a alta demanda e a grande quantidade de carga orgânica lançada nos rios.

Portanto, a escassez pode ser uma ameaça futura também no Brasil, tornando-se necessária uma governança da água bem implementada, primando pelo uso racional do recurso e combatendo o desperdício.

Diante desse quadro geral, considera-se de relevância inegável e de caráter urgente a implementação de visões inovadoras, sistêmicas e integradas, com relação à conceituação e à gestão dos recursos hídricos, que levem em conta sua utilização de acordo com os ciclos hidrogeológicos e que privilegiem sua distribuição e uso de forma socialmente justa.

No contexto dessa gestão cabe salientar a importância para o uso das águas subterrâneas, gênero na qual se enquadram as águas minerais extraídas para fins comerciais e cuja exploração vem aumentando consideravelmente no Brasil e no mundo. Segundo Kulaif (2010) entre 2005 a 2009 a produção total brasileira de água mineral cresceu 50,95\%; no mundo a previsão de crescimento apontava para uma taxa de $4,2 \%$ ao ano. Tais dados justificam uma atenção especial a esse segmento para o entendimento de suas estruturas e institucionalidades, bem como, as formas para integrar sua gestão. 
Dessa forma, o presente artigo visa analisar especificamente a questão das águas minerais, enfatizando o comportamento recente desse mercado no Brasil, os principais direcionamentos legais e institucionais e a gestão ambiental nesse segmento.

Para tanto, foi implantada uma variedade de métodos complementares, como a busca bibliográfica voltada à literatura especializada, o levantamento de dados quantitativos e informações qualitativas, a partir de fontes secundárias, com respeito ao segmento de águas minerais e a pesquisa documental referente às peças legais pertinentes, numa aplicação do método dedutivo.

Procura-se demonstrar a necessidade da alteração do padrão institucional vigente, que considera a água mineral como minério e não como recurso hídrico. $\mathrm{O}$ atual padrão concebe a água mineral não como recurso hídrico, mas sim como um recurso mineral, razão que a coloca sob a proteção do Código de Mineração e do Código de Águas Minerais, em detrimento da Política Nacional de Recursos Hídricos (PNRH).

Argumenta-se que este padrão institucional revela ou "esconde" uma distorção da compreensão da própria natureza do recurso "água mineral", como também evidencia a falta de uma visão sistêmica do próprio ciclo da água.

A revisão desta institucionalidade, defasada e mal instruída do ponto de vista científico, é urgente e essencial para a excelência não somente da gestão ambiental público-privada no segmento das águas minerais, mas também para uma governança integrada e sistêmica dos próprios recursos hídricos de maneira mais abrangente.

Dentro de uma nova institucionalidade, concebida dentro de uma abordagem sistêmica dos recursos hídricos no âmbito da bacia hidrográfica à qual pertencem as águas minerais em cada caso, os agentes econômicos deverão apresentar percepções e adotar compromissos e ações que primem por uma exploração sustentável desse recurso, considerando os limites impostos pela capacidade de renovação dada pelas condições dos ciclos hidrogeológicos e os objetivos mais amplos de preservação dessas fontes como reservas hídricas para o futuro. É dentro desse contexto maior que se devem incluir as necessárias análises e considerações com relação ao ciclo de vida, às ações voltadas ao correto destino dos resíduos gerados na produção, na comercialização e no consumo.

$\mathrm{O}$ artigo encontra-se estruturado em quatro partes, além dessa introdução. No item 1 apresenta-se os dados referentes ao mercado de águas minerais no Mundo e, principalmente, no Brasil demonstrando ainda algumas perspectivas futuras para o segmento. Em seguida, o item 2 discute o atual quadro legal e institucional brasileiro sobre as águas minerais, enfatizando o fato desse recurso ainda ser considerado minério e não hídrico. No item 3 analisam-se os principais direcionamentos para uma exploração mais sustentável desse recurso, enfatizando a necessidade de sua integração na Política Nacional de Recursos Hídricos (PNRH) e na Política Nacional de Resíduos Sólidos (PNRS). Ao final, apresentam-se as considerações finais.

\section{ANÁLISE DO COMPORTAMENTO RECENTE DO MERCADO E SUAS PERSPECTIVAS}

Para a construção desse item utilizam-se principalmente os dados divulgados pelo DNPM (Departamento Nacional de Produção Mineral), por meio de publicações como Sumário Mineral e Anuário Mineral Brasileiro, bem como o estudo realizado pelo Ministério de Minas e Energia a respeito das águas minerais. O uso dessas fontes justifica-se devido ao cuidado que se deve ter quando da realização dessas análises, pois, segundo Kulaif (2010), as estatísticas sobre a produção de água mineral no Brasil não apresentam uma uniformidade quanto à abrangência, sendo algumas delas referentes somente a águas engarrafadas e outras abrangendo essas e mais a água mineral incorporada a produtos industrializados, ingestão na 
fonte ou até mesmo para fins balneários. Outra questão que deve ser explicada é o fato de que as publicações sobre mineração no Brasil referem-se sempre ao ano anterior às mesmas. $\mathrm{O}$ último trabalho publicado sobre águas minerais data de 2010 e refere-se ao ano de 2009 . O Sumário Mineral 2011, referente a 2010, não incluiu os dados sobre água mineral.

Kulaif (2010) indica que, conforme a consultoria Zenith International, em 2009 o mercado mundial apenas de águas engarrafadas atingiu a marca de 215 bilhões de litros, representando um crescimento de 3,9\% em relação ao ano anterior, prevendo-se uma expansão média de 4,2\% ao ano, nos próximos cinco anos.

As quatro maiores empresas do setor dominam, aproximadamente, $30 \%$ do mercado específico de águas engarrafadas no mundo, sendo elas: Nestlé 10,5\%; Danone 8,2\%; Coca-Cola 6,8\% e PepsiCo 4\%. Conforme o MME (Brasil, 2009), considerando-se todo o setor de águas envasadas (incluindo a incorporação em produtos industrializados) o domínio dessas empresas aproxima-se de $50 \%$ do mercado.

A Tabela 1 apresenta os principais mercados consumidores de água mineral engarrafada no mundo. Segundo MME (Brasil, 2009) a China é o país que apresenta a maior expansão no consumo mundial de água mineral, tendo passado de uma participação de 8,7\% em 2004 para $11,02 \%$ em 2009. Outro país com importante expansão nesse segmento foi a Indonésia passando sua participação de 5,2\% para 6,51\%. No Brasil o nível aparente de consumo em 2009 foi de 5,2 bilhões de litros, representando uma participação no consumo mundial de $2,42 \%$, estando também em expansão. Consumo aparente de um bem se refere ao total da produção adicionada das importações e subtraída das exportações.

Tabela 1. Consumo mundial de água mineral engarrafada (em 2009).

\begin{tabular}{lcc}
\hline \multicolumn{1}{c}{ País } & $\begin{array}{c}\text { Consumo } \\
\text { (bilhões de litros) }\end{array}$ & $\begin{array}{c}\text { \% de } \\
\text { participação }\end{array}$ \\
\hline Estados Unidos & 30,8 & 14,33 \\
China & 23,7 & 11,02 \\
México & 16,5 & 7,67 \\
Indonésia & 14,0 & 6,51 \\
Alemanha & 13,0 & 6,05 \\
Itália & 11,0 & 5,12 \\
\hline
\end{tabular}

Fonte: Kulaif (2010).

Segundo o MME (Brasil, 2009), 48,2\% das águas minerais no Brasil são classificadas como fluoretadas; $16,2 \%$ como proveniente de fontes hipo a hipertermal; $14,68 \%$ de fontes radiotivas frias a hipertermais e 10,20\% de potáveis de mesa. Dessa forma, têm-se à disposição da sociedade os mais variados tipos de água em diferentes volumes e embalagens, desde águas mais ricas em sais (bicarbonatadas, alcalinas, alcalinas terrosas, sulfurosas e ferruginosas) até as mais leves (carbogasosas, hipotermais, radiotivas, fracamente radiotivas, fluoretadas, litinadas e potáveis de mesa). As águas mais ricas em sais são oferecidas para ingestão direta na fonte em parques e estâncias hidrominerais. Já as águas leves é que são oferecidas via mercado em embalagens plásticas ou de vidro, com ou sem gás natural ou artificial, bem como, utilizadas como insumo na produção de outras bebidas.

A Tabela 2 apresenta o comportamento da produção total de água mineral no Brasil entre 2005 e 2009, indicando o que foi destinado para engarrafamento e para a composição de produtos industrializados, este último apresenta o que foi usado para a produção de bebidas em geral. 
Tabela 2. Produção brasileira de água mineral (em 1.000 litros).

\begin{tabular}{ccrc}
\hline Ano & Engarrafamento & $\begin{array}{c}\text { Composição de } \\
\text { Produtos } \\
\text { Industriais }\end{array}$ & Total \\
\hline 2005 & 4.270 .301 & 751.326 & 5.021 .627 \\
2006 & 3.978 .935 & 688.078 & 4.667 .013 \\
2007 & 4.017 .412 & 901.101 & 4.918 .513 \\
2008 & 4.746 .208 & 1.795 .453 & 6.541 .661 \\
2009 & 5.323 .779 & 2.256 .496 & 7.580 .275 \\
\hline
\end{tabular}

Fonte: DNPM (2006; 2007; 2010) e Kulaif (2010).

No período considerado percebe-se uma queda na produção de água mineral engarrafada no ano de 2006, com pequena recuperação em 2007, causada principalmente em virtude das incertezas no cenário econômico mundial diminuindo a realização de investimentos por empresas brasileiras e transnacionais, bem como pela reestruturação patrimonial e produtiva pela qual passaram algumas empresas desse segmento, principalmente as tradicionais Caxambu, Cambuquira, Lambari e Araxá em Minas Gerais. Somente a partir de 2008 a empresa Caxambu voltou a produzir. Cambuquira foi reativada em 2011 e as demais (Lambari e Araxá) estão em processo de reativação. Em 2008 e 2009 nota-se uma plena recuperação no segmento de engarrafamento, crescendo $11,14 \%$ e $24,67 \%$, respectivamente, em relação a 2005.

Já o segmento de água mineral destinada à composição de produtos industriais vem apresentando expansão considerável nesses cinco anos, exceto também no ano de 2006, principalmente em virtude dos altos investimentos realizados pelas empresas de bebidas, tanto nacionais como estrangeiras. Em 2005 apenas 14,96\% da produção de água mineral destinava-se a esse fim, em 2009 essa cifra passou para 29,8\%, um crescimento de 200,34\%. Isso ocorreu em virtude da implantação do selo fiscal em alguns estados e de hidrômetros nas empresas de refrigerantes, que auxiliou na obtenção de dados mais reais e precisos sobre a produção (Kulaif, 2010; CPRM, 2011). O selo fiscal é implantado e controlado pelas secretarias estaduais de receita, visando, principalmente, um maior controle da produção e o combate à informalidade e clandestinidade do setor. A implantação do selo está sendo realizado a critério de cada Estado da federação, o que demonstra uma falta de articulação a nível nacional desse processo, o que permitiria um maior controle e fiscalização da exploração desse recurso.

Em virtude do exposto, a produção total em 2006 também apresentou queda de 7,06\% em relação a 2005, sendo que não foi compensada em 2007, quando ainda apresentava um nível 2,05\% abaixo do de 2005. Porém, em 2008 e 2009 a produção total viria a recuperar-se plenamente com níveis 30,27\% e 50,95\%, respectivamente, maiores que 2005.

Cabe, mais uma vez salientar, que esses valores são considerados extremamente conservadores, pois, consultorias internacionais do setor de bebidas indicam que a produção de água mineral engarrafada no Brasil seria o dobro, ou até mesmo o triplo do montante declarado. Porém, como o DNPM é o órgão principal desse setor, optou-se nesse trabalho por manter e analisar esses dados que são considerados os oficiais do setor (Kulaif, 2010). No entanto, tal fato mostra a necessidade de uma melhor governança dos recursos hídricos a fim de que os órgãos envolvidos possam resolver esse problema de informações desencontradas sobre a exploração do recurso. 
A Tabela 3 apresenta os dez estados brasileiros com maior nível de produção total no ano de 2009, apresentando seus respectivos destinos para engarrafamento e composição de produtos industriais.

Tabela 3. Dez maiores estados produtores segundo a produção total em 2009.

\begin{tabular}{|c|c|c|c|c|c|c|}
\hline \multirow[b]{2}{*}{ Estado } & \multicolumn{2}{|c|}{ Engarrafamento } & \multicolumn{2}{|c|}{$\begin{array}{c}\text { Composição de Produtos } \\
\text { Industriais }\end{array}$} & \multicolumn{2}{|c|}{ TOTAL } \\
\hline & Qtde. (1.000 L) & Valor (R\$) & Qtde. (1.000 L) & Valor $(\mathrm{R} \$)$ & Qtde. (1.000 L) & Valor (R\$) \\
\hline SP & 980.746 & 327.716 .132 & 797.245 & 14.064 .650 & 1.777 .991 & 341.780 .782 \\
\hline BA & 366.518 & 94.527 .237 & 973.885 & 31.764 .177 & 1.340 .403 & 126.291 .414 \\
\hline PE & 876.622 & 70.604 .974 & 415.287 & 332.230 & 1.291 .910 & 70.937.204 \\
\hline RJ & 381.174 & 71.422 .688 & - & - & 381.174 & 71.422 .688 \\
\hline MG & 369.136 & 118.576 .505 & 510 & 97.136 & 369.646 & 118.673 .641 \\
\hline RS & 237.635 & 134.585 .169 & - & - & 237.635 & 134.585 .169 \\
\hline PA & 222.860 & 30.162 .435 & - & - & 222.860 & 30.162 .435 \\
\hline $\mathrm{CE}$ & 205.006 & 63.236 .887 & 55 & 55.000 & 205.061 & 63.291 .887 \\
\hline PR & 201.784 & 60.142 .390 & 75 & 48.599 & 201.859 & 60.190 .989 \\
\hline $\mathrm{AM}$ & 148.021 & 32.004 .107 & 28.874 & 2.887 .416 & 176.895 & 34.891 .523 \\
\hline
\end{tabular}

Fonte: DNPM (2010).

Nessa tabela é possível notar alguns destaques importantes: o estado de São Paulo como o maior produtor total e para engarrafamento; a Bahia é o maior produtor de água mineral destinada à composição de produtos industriais, seguida por São Paulo e Pernambuco, estando esses três estados bem distantes dos demais, isso se deve principalmente às empresas de refrigerantes e cervejas que se localizam nesses estados, com destaque para a Primo Schincariol Indústria de Cervejas e Refrigerantes do Nordeste S/A cujas fábricas se encontram na Bahia e Pernambuco. As diferenças nos valores em unidades monetárias, com destaque para Minas Gerais e Rio Grande do Sul, devem-se ao fato de suas águas minerais serem de uma tipologia de melhor qualidade e mais valorizada no mercado.

Conforme DNPM (2010) o destino da produção brasileira é quase totalmente para o mercado interno, sendo os cinco principais estados consumidores e respectivas participações: SP 25,96\%; PE 14,14\%; RJ 6,99\%; BA 6,50\%; e MG 5,11\%.

Apenas uma pequena fatia de $0,015 \%$ da produção total destina-se à exportação, sendo que em 2009, atingiu-se a cifra de US\$ 963.000,00 FOB (Free On Board). Os principais destinos da água mineral brasileira exportada em 2009 foram: Japão com 89.76\% do total exportado; Angola 4,24\%; Paraguai 1,61\%; Chile 1,32\%; e Guiana com 1,20\%; os outros destinos somados totalizam $1,87 \%$.

Já a importação totalizou em 2009 US\$ 709.000,00 FOB, sendo os principais fornecedores: França com 52\%; Itália 36\%; Uruguai 10\%; Portugal e Japão juntos 2\%.

Nota-se que o comércio exterior de águas minerais no Brasil é pouco explorado e com baixa participação no montante total da produção. Mesmo assim, o país apresentou uma balança comercial superavitária nesse segmento em 2009 no valor de US\$ 254.000,00 FOB.

Segundo o MME (Brasil, 2009) o segmento empresarial de água mineral no Brasil é composto por duas categorias:

- As grandes empresas/grupos nacionais e multinacionais;

- As micros, pequenas e médias empresas nacionais

As primeiras seguem, tanto em funcionamento quanto em investimento, o modelo europeu e norte americano. Já a Nestlé, de origem suíça, Danone, de origem francesa e CocaCola de origem norte americana, mesmo aqui no Brasil, seguem a orientação de suas sedes e 
investem na pesquisa em novas fontes, aquisição de empresas locais e novos posicionamentos de mercado.

Já em relação à segunda categoria, muitas são empresas familiares, fracamente capitalizadas e culturalmente adversas a investimentos em pesquisa. Esperam sempre que a atitude de investimentos em pesquisa tenha sua origem no governo federal, estadual ou mesmo municipal.

As Tabelas 4 e 5 apresentam as dez principais empresas produtoras nos anos de 2005 e 2009, respectivamente, incluindo informações sobre o grupo empresarial a qual pertencem, principais marcas, os Estados onde ocorreu a comercialização e/ou o consumo da produção beneficiada, bem como, a participação percentual no mercado.

Tabela 4. Principais empresas produtoras em 2005.

\begin{tabular}{|c|c|c|c|c|}
\hline Empresa & $\begin{array}{c}\text { Grupo } \\
\text { Empresarial }\end{array}$ & Principais marcas & UF & $\begin{array}{c}\% \\
\text { Mercado } \\
\end{array}$ \\
\hline $\begin{array}{l}\text { Spal Indústria Brasileira de Bebidas } \\
\text { S/A }\end{array}$ & Coca-Cola & Crystal & SP & 9,97 \\
\hline Indaiá Brasil Águas Minerais & Edson Queiroz & Indaiá & $\begin{array}{l}\text { AL, BA, CE, } \\
\text { DF, GO, MA, } \\
\text { MG, PA, PB, } \\
\text { PE, RN, SE. }\end{array}$ & 8,14 \\
\hline $\begin{array}{l}\text { Nestlé Waters Brasil - Bebidas e } \\
\text { Alimentos Ltda. }\end{array}$ & Nestlé & $\begin{array}{l}\text { São Lourenço e } \\
\text { Petrópolis }\end{array}$ & MG e RJ & 6,75 \\
\hline $\begin{array}{l}\text { Primo Schincariol Ind. de Cervejas } \\
\text { e Refrigerantes S/A }\end{array}$ & Schincariol & Schin & GO e SP & 5,36 \\
\hline Minalba Alimentos e Bebidas Ltda & Edson Queiroz & Minalba & SP & 4,10 \\
\hline Refrigerantes Coroa Ltda. & Coroa & Campinho & $\mathrm{ES}$ & 4,06 \\
\hline Mocellin e Cia Ltda. & Ouro Fino & Ouro Fino & PR & 3,93 \\
\hline Empresa Mineradora Ijuí S/A & CVI & Fonte Injuí & $\mathrm{RS}$ & 3,84 \\
\hline Águas Minerais Sarandi Ltda. & Sarandi & $\begin{array}{l}\text { Fonte Sarandi e } \\
\text { Fonte Floresta }\end{array}$ & $\mathrm{RS}$ & 3,28 \\
\hline Empresa Mineradora Charruá Ltda. & CVI & Charruá & $\mathrm{RS}$ & 3,00 \\
\hline
\end{tabular}

Fonte: DNPM (2006).

A análise dessas duas tabelas permite verificar importantes mudanças no ranking das principais empresas de águas minerais no Brasil em um breve intervalo de cinco anos. $\mathrm{O}$ fato que merece maior atenção é a expansão do Grupo Edson Queiroz (Indaiá e Minalba) que em 2005 detinha 12,24\% de participação total no mercado, já em 2009 essa participação sobe para $21,61 \%$, sendo as únicas empresas que apresentaram aumento, todas as demais tiveram sua fatia de mercado diminuída.

As dez maiores empresas em 2005 somadas detinham 52,43\% do mercado, em 2009 a participação das dez maiores caíram para 48,68\%. Porém, essa análise deve ser vista com reservas, pois, ao verificar a participação somente das quatro maiores empresas em 2005 somavam 30,22\%, enquanto que em 2009 detinham conjuntamente $32,17 \%$, exclusivamente em função da expansão do Grupo Edson Queiroz, com destaque para a Indaiá. Conforme Mendes (2005) um índice de concentração das quatro maiores firmas abaixo de $40 \%$ significa que esse mercado apresenta baixa concentração, com provável concorrência entre elas e baixa possibilidade de conluio. 
Tabela 5. Principais empresas produtoras em 2009.

\begin{tabular}{|c|c|c|c|c|}
\hline Empresas & $\begin{array}{c}\text { Grupo } \\
\text { Empresarial }\end{array}$ & Principais marcas & UF & $\begin{array}{c}\% \\
\text { Mercado }\end{array}$ \\
\hline Indaiá Brasil Águas Minerais & Edson Queiroz & Indaiá & $\begin{array}{l}\text { AL, BA, CE, } \\
\text { DF, GO, MA, } \\
\text { MG, PA, PB, } \\
\text { PE, SE. }\end{array}$ & 15,91 \\
\hline $\begin{array}{l}\text { Spal Indústria Brasileira de Bebidas } \\
\text { S/A }\end{array}$ & Coca-Cola & Crystal & SP & 5,84 \\
\hline Minalba Alimentos e Bebidas Ltda. & Edson Queiroz & Minalba & $\mathrm{SP}$ & 5,70 \\
\hline $\begin{array}{l}\text { Nestlé Waters Brasil - Bebidas e } \\
\text { Alimentos Ltda }\end{array}$ & Nestlé & $\begin{array}{l}\text { São Lourenço, } \\
\text { Petrópolis e } \\
\text { Pureza Vital }\end{array}$ & $\mathrm{MG}, \mathrm{RJ}$ e SP & 4,72 \\
\hline Mocellin e Cia Ltda. & Ouro Fino & Ouro Fino & PR & 3,23 \\
\hline Fountain Água Mineral & $\begin{array}{l}\text { Spaipa e Coca- } \\
\text { Cola }\end{array}$ & Crystal & SP & 2,97 \\
\hline CPN Mineração Ltda. & Danone & Icoara/Bonafont & MG & 2,75 \\
\hline $\begin{array}{l}\text { Schincariol Empresa de Mineração } \\
\text { Ltda. }\end{array}$ & Schincariol & Schin & SP & 2,75 \\
\hline Empresa Mineradora Ijuí S/A & CVI & Fonte Injuí & RS & 2,39 \\
\hline $\begin{array}{l}\text { Primo Schincariol Ind. de Cervejas e } \\
\text { Refrigerantes S/A }\end{array}$ & Schincariol & Schin & $\mathrm{BA}, \mathrm{PE}$ & 2,38 \\
\hline
\end{tabular}

Fonte: DNPM (2010).

Outro fato importante é a maior presença de empresas multinacionais entre as dez maiores do segmento. Em 2005 apenas duas figuravam na lista, Coca-Cola e Nestlé Waters, já em 2009 somam-se quatro empresas com participação direta ou indireta de multinacionais na lista, e são elas: Coca-Cola na Spal Indústria Brasileira de Bebidas e na Fountain Água Mineral, Nestlé-Waters e a Danone que, mesmo sem possuir título minerário no Brasil, comprou a empresa Icoara Indústria e Comércio de Águas S/A de Jacutinga - MG que pertencia ao Grupo CPN, atribuindo-lhe a marca Bonafont.

Cabe ainda citar que em 2007 o Grupo Companhia Vontobel de Investimentos (CVI) realizou um processo de permuta de ações e de quotas com a Coca-Cola, passando esta última a deter 50\% das ações da Charruá Águas Ltda., localizada no Rio Grande do Sul.

Nota-se assim, perspectivas de participação mais efetiva das empresas multinacionais no mercado de água mineral no Brasil. Fato esse corroborado pelo MME (Brasil, 2009) ao afirmar que, com a aquisição pela Nestlé Waters Brasil da água Santa Bárbara (SP) e com os investimentos e início da produção da água Bonafont pela Danone em Jacutinga (MG), o mercado de água mineral envasada no Brasil deverá sofrer alterações significativas nos próximos anos e o capital estrangeiro, que até 2008 participava timidamente do mercado brasileiro, deverá ampliar consideravelmente sua participação.

Conforme CPRM (2011) a PepsiCo, quarta maior produtora mundial, pretende instalar uma fábrica em São Paulo ou na Bahia nos próximos anos onde deverá envasar a água Aquafina, segunda marca de água envasada mais vendida nos Estados Unidos.

Tais processos de aquisição de pequenas empresas nacionais por grupos multinacionais demonstram a importância desse mercado para esses grandes players internacionais. Muito mais do que uma reestruturação patrimonial, esses movimentos indicam uma tendência de concentração de capital nesse setor, visto se tratar de um recurso estratégico para essas grandes multinacionais e cujo acesso no mundo está ficando cada vez mais restrito. Tal fato 
implica na necessidade de um controle do acesso desses grandes grupos, sejam nacionais ou internacionais, à exploração de águas minerais no Brasil.

Ainda com relação às perspectivas de mercado, o DNPM (2010) divulgou os investimentos previstos para os próximos três anos no segmento de águas minerais no Brasil. $\mathrm{O}$ valor total previsto é de $\mathrm{R} \$ 251.094 .942,00$, indicando uma média anual de $\mathrm{R} \$$ 83.698.314,00, valor esse $10 \%$ maior do que o nível de investimento no ano de 2009; porém, o órgão não assigna os valores dos investimentos por empresa, mas somente as categorias que receberão esses investimentos e os Estados nos quais estes serão realizados.

A distribuição dos investimentos previstos para os próximos três anos entre as categorias do segmento apresenta a seguinte relação:

- Aquisição e/ou reforma de equipamentos: 39,20\%

- Instalação de engarrafamento: $22,20 \%$

- Infraestrutura: $12,20 \%$

- Instalação de balneários e/ou hoteleiras: 3,30\%

- Outros: $23,10 \%$

Nota-se que a parte mais expressiva dos investimentos previstos volta-se às categorias diretamente relacionadas à pesquisa de novas fontes e capacidade de produção, com um baixo destino de recursos para as áreas de crenologia e ecoturismo, demonstrando assim a finalidade puramente produtiva dos recursos a serem empregados.

Os Estados que serão os principais destinos dos investimentos previstos para os próximos três anos são: São Paulo com 21,49\% dos investimentos totais; Minas Gerais com 11,11\%; Paraná 9,35\%; Pará com 5,47\%; e Rio de Janeiro 5,44\%.

A Tabela 6 apresenta os montantes que deverão ser investidos nesses Estados divididos de acordo com cada uma das categorias do segmento. Optou-se por apresentar aqui somente os cinco principais Estados que receberão esses investimentos, salientando que a fonte pesquisada não informa a origem de tais recursos, deduzindo-se que deverão ser principalmente, privados.

Tabela 6. Principais estados alvos dos investimentos previstos de 2010-2012 (em R\$).

\begin{tabular}{lrrccrr}
\hline Estado & $\begin{array}{c}\text { Aquisição e/ou } \\
\text { reforma de } \\
\text { equipamentos }\end{array}$ & Infraestrutura & $\begin{array}{c}\text { Instalações } \\
\text { Balneárias / } \\
\text { hoteleiras }\end{array}$ & $\begin{array}{c}\text { Instalações de } \\
\text { engarrafamento }\end{array}$ & Outros & Total \\
\hline SP & 25.521 .600 & 6.407 .600 & 421.000 & 10.937 .500 & 10.669 .900 & 53.957 .600 \\
MG & 9.480 .600 & 5.582 .700 & 593.360 & 6.227 .200 & 6.003 .560 & 27.887 .420 \\
PR & 8.399 .000 & 2.116 .200 & 2.310 .000 & 7.429 .000 & 3.234 .500 & 23.488 .700 \\
PA & 11.565 .000 & 721.000 & - & 1.029 .000 & 416.000 & 13.731 .000 \\
RJ & 2.704 .600 & 1.819 .350 & - & 4.684 .500 & 4.458 .220 & 13.666 .670
\end{tabular}

Fonte: DNPM (2010).

Cumpre atentar-se para o fato de que o Estado do Pará é o que deve apresentar maior evolução de produção nos próximos anos, o que se explicaria pelo fato de possuir grandes reservas de água mineral de fácil acesso, em razão de seu solo ter-se formado a partir de sedimentos. O Pará é considerado o segundo maior Estado brasileiro em potencial hídrico (Araújo, 2009). Essa possibilidade de aumento da produção fica evidente na análise da tabela 6 onde se visualiza que a maior parte dos investimentos previstos tem como destino a aquisição e/ou reforma de equipamentos para a exploração do recurso. 
Configura-se assim a possibilidade de importantes mudanças no segmento de águas minerais no Brasil nos próximos anos, principalmente no que tange o surgimento de novas regiões produtoras e fortalecimento das já existentes, além de um aumento no mercado consumidor, principalmente pelo fato da população urbana já não considerar de boa qualidade as águas provenientes das empresas de abastecimento e saneamento. Presume-se ainda que deva ocorrer um processo de evolução e seleção nesse segmento, ocasionando uma provável concentração de mercado, com as pequenas empresas, que competem via redução de preços, não resistindo ao avanço dos grandes grupos, seja por se tornarem alvos de aquisição, seja por sua simples eliminação no processo concorrencial.

\section{O QUADRO LEGAL E INSTITUCIONAL}

Nesse item procura-se apresentar as diretrizes legais mais importantes sobre a exploração de águas minerais no Brasil, buscando demonstrar a importância de uma relação mais estreita entre essas legislações específicas e a Política Nacional de Recursos Hídricos.

A questão ambiental no Brasil está inserida atualmente, de uma forma geral, na Constituição Federal de 1988, onde se afirma que todos têm o direito ao meio ambiente ecologicamente equilibrado, bem de uso comum do povo e essencial à sadia qualidade de vida, impondo-se ao poder público e à coletividade o dever de defendê-lo e preservá-lo para a presente e futuras gerações (Brasil, 1988).

Porém, muito antes da promulgação da lei magna do País, algumas questões referentes ao meio ambiente já figuravam em leis específicas. O tratamento legal dado às águas é uma dessas questões, já que desde a década de 1940 já existem leis que tratam de forma direta sobre as águas minerais.

Importante ressaltar, conforme Ninis (2006), que até a década de 1930 a Constituição de 1891 previa a agregação da propriedade do subsolo à propriedade do solo. Porém, na Constituição de 1934 foi alterada essa questão, estabelecendo que as minas e jazidas tivessem sua propriedade distinta do solo, ou seja, estabeleceu-se a distinção entre propriedade mineral e territorial. Também é neste mesmo ano de 1934 que surge o primeiro Código de Minas que mais tarde sofreria alterações.

A água, em virtude de suas características intrínsecas, recebe um tratamento legal diferenciado segundo sua fonte e utilização. Segundo Obata et al. (2005) como recurso mineral, a água é bem da União, estando seu aproveitamento regido pelo Código de Águas Minerais (Decreto Lei 7.841 08/08/1945) conjugado com o Código de Mineração (Decreto Lei 227, 27/02/1967) e legislação correlata, cuja aplicação é de responsabilidade do Departamento Nacional da Produção Mineral (DNPM), órgão do Ministério de Minas e Energia. Já como recurso hídrico é um bem público da União ou dos Estados, sendo sua utilização subordinada ao Plano Nacional de Recursos Hídricos (que se trata de um instrumento de aplicação instituído pela Lei 9.433/1997) da Secretaria de Recursos Hídricos e Ambiente Urbano do Ministério do Meio Ambiente, gerenciada pelo Sistema Nacional de Gerenciamento dos Recursos Hídricos. Essa última Lei caracteriza-se por uma descentralização do processo operacional e decisório, transparência e publicidade na execução das ações, podendo inclusive estabelecer a cobrança pelo uso da água, tendo como seus importantes órgãos os Comitês de Bacias Hidrográficas e as Agências de Águas.

As águas minerais, de forma particular, são consideradas em um contexto de jazidas regidas por leis especiais, sendo que, até a determinação da Portaria de Lavra, seguem-se os mesmos determinantes de qualquer outro mineral, após a obtenção da lavra a exploração passa a seguir determinações específicas (Brasil, 1945). O mesmo código, em seu artigo $1^{\circ}$, define águas minerais como sendo "aquelas provenientes de fontes naturais ou de fontes artificialmente captadas que possuam composição química ou propriedades físicas ou 
físico-químicas distintas das águas comuns, com características que lhes confiram uma ação medicamentosa." Importante salientar também a existência da água potável de mesa (água natural) também regida por esse código e definida no artigo $3^{\circ}$ como sendo aquelas de "composição normal provenientes de fontes naturais ou de fontes artificialmente captadas que preencham tão somente as condições de potabilidade para a região".

$\mathrm{O}$ artigo $4^{\circ}$ do Código de Águas Minerais determina que o "aproveitamento comercial das fontes de águas minerais ou de mesa, [...] far-se-á pelo regime de autorizações sucessivas de pesquisa e lavra, instituído pelo Código de Mineração, observadas as disposições especiais da presente lei."

Sendo assim, a água envasada e comercializada possui dois tipos de classificação: a água mineral propriamente dita, que é uma espécie do gênero água subterrânea contendo elementos e teores de sais minerais, que lhe dão uma qualidade terapêutica e medicamentosa; e a água natural que é captada da mesma forma, porém sem apresentar aqueles elementos característicos (Guimarães, 2008). Além disso, o Código de Águas Minerais trata dos aspectos particularizados intrínsecos a essa substância em termos de classificação, pesquisa, captação, envase e características das respectivas instalações.

Cabe ainda salientar que, em termos ambientais, os artigos 12 e 13 do Código de Águas Minerais determinam que nas fontes de exploração de água mineral poderá ser estabelecido, por meio de decreto, um perímetro de proteção, sujeito a modificações posteriores caso seja necessário; e que nenhuma sondagem ou trabalho subterrâneo poderá ser realizado em tal perímetro sem a autorização prévia do DNPM.

Segundo o Código de Mineração (Brasil, 1967) a lavra de água mineral somente deve ser requerida por pessoa jurídica, sendo necessário o requerimento inicial de pesquisa por meio de um projeto cuja área máxima é de 50 ha. $\mathrm{O}$ alvará de pesquisa terá dois anos de prazo a partir de sua publicação, podendo ser prorrogado por igual período até mais de uma vez, tendo a possibilidade de ser cedido e/ou transferido e, também, renunciado. Após o prazo de pesquisa deve-se apresentar um Relatório Final de Pesquisa.

No que tange o Sistema Nacional de Gestão dos Recursos Hídricos (SRHU) a Lei 6.101/2007 (Brasil, 2007a) em sua Seção II Art. 23 instituiu a esse órgão duas competências que envolvem, de maneira indireta, a gestão das águas minerais, são elas:

$\checkmark$ Item V: coordenar, em sua esfera de competência, a elaboração de planos, programas e projetos nacionais, referentes a águas subterrâneas, e monitorar o desenvolvimento de suas ações, dentro do princípio da gestão integrada dos recursos hídricos;

$\checkmark$ Item XII: promover, em articulação com órgãos e entidades estaduais, federais e internacionais, os estudos técnicos relacionados aos recursos hídricos e propor o encaminhamento de soluções.

Percebe-se certa discrepância nos ditames legais referentes à água mineral que, conforme Caetano (2005) pode levar a certo conflito em virtude do fato de se tratarem de prerrogativas legais de diferentes épocas e situações políticas no Brasil, sendo que a Política Nacional dos Recursos Hídricos (PNRH) é de 1997 (período democrático, descentralizador e participativo) e os Códigos de Mineração e de Águas Minerais são, respectivamente, de 1967 e 1945 (períodos de regimes autoritários e centralizadores). Cabe salientar que o Código de Mineração passou por algumas reestruturações, uma delas inclusive em 2012, porém, a parte referente às águas minerais e o seu código específico continuam sem mudanças mesmo com a expansão da exploração desse recurso.

Verifica-se, portanto, a existência de uma divergência na aplicação do comando e controle em virtude da existência de dois instrumentos institucionais distintos, o Código de Águas Minerais e a Política Nacional de Recursos Hídricos, que tratam do mesmo recurso: a 
água. A resolução dessa divergência somente será possível por meio da integração das águas minerais na gestão de recursos hídricos.

Esse processo de integração vem sendo alvo de discussões e debates há algum tempo, envolvendo órgãos e instituições como ABINAM (Associação Brasileira de Indústria de Água Mineral), CNI (Confederação Nacional da Indústria), DNPM, Conselho Nacional de Recursos Hídricos, Agência Nacional de Águas, Secretarias Estaduais de Recursos Hídricos, Comitês de Bacia Hidrográfica e, até mesmo, associações de moradores de cidades com balneários de águas minerais; porém, sem uma solução definitiva e de comum acordo. Ainda conforme Caetano (2005) existem divergências consideráveis, pois de um lado estão os representantes do setor mineral e das indústrias representados, principalmente, por DNPM, ABINAM e CNI que defendem a obediência fiel e indiscutível às legislações minerais de 1945 e 1967. De outro lado encontram-se os órgãos de gestão de recursos hídricos estaduais e federais, bem como as entidades ambientais e associações de moradores, que aclamam pelo cumprimento da Constituição de 1988 e da lei 9.433/1997 (PNRH) (Brasil, 1997).

Cada um dos lados fundamenta sua posição da seguinte maneira:

- para o setor mineral e industrial, a água mineral é um recurso nobre e de qualidade superior às águas subterrâneas, sendo assim, não podem fazer parte de uma gestão integrada de um recurso ao qual não pertencem. Sua instância de discussão e defesa de seus interessados está concentrada essencialmente no Ministério de Minas e Energia. Haja visto, que a recente mudança do Código de Mineração não abarcou em nenhum momento o debate sobre a gestão das águas minerais;

- para os órgãos gestores dos recursos hídricos a água mineral não é assim tão nobre que não possa participar de uma gestão unificada, afinal todas as águas são nobres em sua essência, unidas direta e indiretamente pelo ciclo hidrogeológico e para seu aproveitamento sustentável devem ser geridas de forma integrada, com a participação de diversos setores e atores da sociedade. Tais discussões ocorrem principalmente nos âmbitos do Conselho Nacional de Recursos Hídricos e Ministério do Meio Ambiente, além do amplo envolvimento de Comitês de Bacia Hidrográfica e associações de moradores de municípios com exploração de águas minerais. As ONGs ambientais, juntamente com essas associações de moradores, chamam a atenção para a exploração irracional desse recurso, principalmente quando as empresas locais são adquiridas por grandes grupos nacionais e multinacionais.

Um passo para essa integração entre PNRH e as águas minerais foi dado pela Resolução 76/2007 (Brasil, 2007b) do Conselho Nacional de Recursos Hídricos que estabeleceu as diretrizes gerais para a integração da gestão de recursos hídricos e a gestão de águas minerais, termais, gasosas, potáveis de mesa ou destinadas a fins balneários. O intuito maior dessa resolução é promover o intercâmbio de informações e compatibilização de procedimentos entre o órgão gestor dos recursos hídricos e o órgão gestor de recursos minerais.

$\mathrm{O}$ trâmite básico a ser seguido se inicia com o recebimento do requerimento de autorização para pesquisa de água mineral pelo órgão gestor de recursos minerais (DNPM) que dará conhecimento do mesmo para o órgão gestor de recursos hídricos, que deverá analisar e informar ao DNPM apenas duas questões: 1) se existem outorgas de direito de uso de recursos hídricos, demais atos autorizativos e os usos cadastrados existentes na área requerida para pesquisa e em seu entorno; e 2) se existem áreas de restrição e controle que possam ter interferência com a área requerida.

Percebe-se que a integração proposta pela resolução é muito restrita e não abarca questões de suma importância como a cobrança pelo uso da água mineral, a situação das empresas já estabelecidas, as ações pertinentes ao Comitê de Bacia, a limitação de autorização para exploração comercial de águas minerais por uma mesma empresa ou grupo empresarial, dentre outras importantes considerações. 
Uma maior integração entre o Plano Nacional dos Recursos Hídricos e a exploração comercial das águas minerais tende a ser de considerável importância, afinal permitirá uma participação e fiscalização mais efetiva dos Comitês de Bacia Hidrográfica nesse segmento e a própria cobrança pelo uso exploratório da água, tendo por foco a utilização sustentável do recurso de acordo com sua capacidade de regeneração via ciclo hidrogeológico.

Tal integração também será importante para as empresas de águas minerais, pois permitirá uma melhor relação com as sociedades locais e com as tomadas de decisões dos comitês, evitando processos e ações judiciais pelo uso indiscriminado do recurso, como também, objeções por parte da comunidade onde se localiza a empresa. Soma-se a isso o fato de não ser mais necessário o pagamento da Compensação Financeira pela Exploração Mineral (CFEM), sendo substituída pela cobrança pelo uso da água.

Corrobora com essa discussão o fato de que a extração de água mineral ou potável de mesa diferencia-se das demais indústrias extrativas minerais nos seguintes aspectos, conforme MME (Brasil, 2009):

- Sua ocorrência é mais disseminada pelo planeta.

- As pesquisas geológicas são mais voltadas para a área de hidrogeologia onde clima, vegetação, permeabilidade e sistemas de fraturamento são importantes para a indicação da jazida.

- A frente de lavra é pontual, com captação em surgência ou poço, a maioria dos outros minerais tem uma lavra extensiva.

- A água mineral ou potável de mesa pode ser infinita se mantidas as condições ambientais e climáticas da região e, principalmente, respeitando a capacidade de recarga do aquífero. Os demais recursos minerais têm suas reservas finitas.

- A definição da jazida exige padrões microbiológicos de qualidade para sua utilização na indústria de envase.

- Seu aproveitamento está voltado para a área de alimentos e bebidas e, em alguns casos, para a medicamentosa por meio de ingestão na fonte, banhos, duchas e gargarejos.

- Há uma interface direta entre a água como recurso hídrico subterrâneo e como recurso mineral, que ainda não foi bem estabelecida.

\section{OS DIRECIONAMENTOS DE GESTÃO AMBIENTAL NESSE SEGMENTO}

O segmento de águas minerais também deve seguir padrões de gestão ambiental, porém seu modo de aplicação é diferenciado dos demais segmentos de exploração de recursos minerais. Isso ocorre pelo fato de que no caso das águas minerais a maior parte das degradações ocasionadas não possui gravidade da mesma natureza de outros recursos como, por exemplo, no caso da exploração do minério de ferro.

Porém, mesmo com essa peculiaridade, a questão da exploração sustentável deve ser devidamente considerada pelas empresas de águas minerais. Rosa (1999) informa que nesse segmento o montante gasto com a preservação ambiental tem um caráter muito mais preventivo do que corretivo, exatamente por tentar evitar qualquer tipo de degradação que provocaria sérios danos na lavra e no próprio produto.

Um dos mais sérios problemas ambientais que ocorre nesse segmento refere-se à sobre-exploração das fontes de águas minerais, que podem provocar sérios danos como o rebaixamento do terreno no perímetro da lavra, a secagem da fonte e a perda das características físico-químicas do recurso. Tal fato advém, na maioria das vezes, da ausência de uma fiscalização mais efetiva sobre as empresas, contribuindo para esse tipo de comportamento que pode levar a uma insustentabilidade no uso da água mineral. 
Além desse sério problema, Rosa (1999) aponta o uso de embalagens pelas empresas para a comercialização do produto como outra questão que merece análise profunda, levando em consideração todo o ciclo de vida do produto. Pois, o uso de tais embalagens, principalmente de material plástico, contribui diretamente para a produção de lixo e impacto ambiental quando da sua disposição final incorreta.

Ainda para o mesmo autor outra preocupação na gestão ambiental de empresas de água mineral refere-se à implementação de áreas de preservação no entorno de fontes, denominadas áreas de proteção à captação ou perímetros de proteção ao poço, para evitar a infiltração de substâncias poluentes.

Tal fato é de suma importância, pois, segundo o MME (Brasil, 2009) a maior parte da água mineral no Brasil encontra-se em aquíferos rasos, de fluxos locais e de rápido tempo de trânsito, sendo assim de elevada vulnerabilidade ambiental, necessitando de um correto estabelecimento das áreas de proteção a fim de evitar futuras contaminações.

No Brasil esse zoneamento de proteção é estabelecido pelo DNPM, que adota modelos já aplicados em outros países. Como o ciclo hidrogeológico da água mineral é muito longo, a preocupação com qualquer tipo de impacto ambiental deve ser considerada, pois, caso ocorra uma degradação, os investimentos serão muito altos e o tempo para sua recuperação será relativamente extenso.

A expansão industrial e urbana também agrava o risco de um impacto na qualidade da água mineral, o que preconiza implantações de parques naturais hidrogeológicos, a fim de reforçar o processo de proteção ambiental.

Tachizawa (2005) relaciona algumas estratégias ambientais genéricas que devem ser comuns no segmento industrial do qual faz parte a indústria de água mineral:

- mudança na composição, desenho e embalagem do produto para tornar seu uso menos prejudicial à saúde humana e ao meio ambiente;

- redução do uso de matérias-primas por qualidade de produto fabricado ou substituição da fonte de energia utilizada;

- reciclagem das embalagens utilizadas na comercialização do produto;

- seletividade de fornecedores e distribuidores ambientalmente corretos;

- expansão dos investimentos em controle ambiental;

- desenvolvimento e aperfeiçoamento de sistemas de auditoria ambiental;

- realização e participação em projetos sociais de meio ambiente;

- investir na imagem ambiental da empresa para fins de marketing.

Entretanto, entende-se que estas estratégias gerais devem ser a base do planejamento da gestão ambiental de quaisquer empresas seja qual for seu segmento. Tratando-se das empresas no ramo de água mineral, essas medidas não serão únicas, principalmente devido às especificidades do setor. Sendo assim, estratégias complementares devem ser utilizadas com a finalidade de contribuir efetivamente com a sustentabilidade, além de se obter vantagens competitivas.

Uma dessas especificidades refere-se ao fato de que a água utilizada no processo de produção e a geração de resíduos minerais nesse segmento se confundem afinal a água é o próprio "minério". Dessa forma, segundo MME (Brasil, 2009), as determinações legais brasileiras estabelecem que o último enxágue dos vasilhames retornáveis seja realizado com a água da própria fonte captada e autorizada pelo DNPM e ANVISA. Soma-se a isso a determinação da Portaria 374/2009 do DNPM (2009) de que toda a água usada no enxágue final deve ser reaproveitada para outras lavagens intermediárias ou utilizadas para outros fins na indústria. 
Ainda segundo o mesmo autor a indústria de águas minerais pode gerar outros tipos de resíduos, a saber:

- resíduos líquidos no processo de sanificação, sejam na limpeza ou na desinfecção por meio de detergentes e desinfetantes;

- resíduos sólidos, como restos e aparas de embalagens, papéis de rótulos, caixas de papelão, lacres, tampas de metal e/ou de plástico;

- resíduos gasosos, como o $\mathrm{CO}_{2}$ gerado pela queima de lenha para utilização em caldeiras e na queima de óleo diesel utilizado nos geradores.

Mesmo com todas essas considerações sobre a gestão ambiental nas empresas de águas minerais, nenhuma empresa, até julho de 2009, possuía a certificação ISO 14.001 e apenas cinco empresas possuíam a ISO 9.001, de acordo com o MME (Brasil, 2009) baseado em dados do INMETRO.

A falta da aplicação correta de uma gestão ambiental por essas empresas pode trazer consequências graves não apenas a ela, mas a toda a comunidade, podendo impactar as atividades turísticas, a tradição, o comércio e os serviços locais, bem como, causar a perda de referência da identidade histórico-social da cidade.

Além dessas considerações sobre a gestão ambiental nesse setor outra especificidade deve ser considerada: a exclusividade das águas minerais. Conforme Ninis (2006), cada água mineral possui uma composição própria, não existindo uma água mineral igual à outra, mesmo que ambas sejam da mesma marca comercial, se forem captadas em fontes diferentes, essas águas não serão iguais. Sendo assim, mesmo se tratando de um recurso renovável, sua exploração deve considerar certos fatos como a capacidade de recarga e a vulnerabilidade à degradação, a fim de evitar perdas que podem ser irreversíveis.

Dessa forma, fica claro que deve haver um acordo entre a percepção por parte das empresas de água mineral sobre a importância da gestão ambiental e a aplicabilidade e participação das mesmas no processo de gerenciamento e preservação dos recursos hídricos e do meio ambiente.

Para tanto e primeiramente, as empresas devem considerar, em seu gerenciamento ambiental, a importância de se pensar numa forma de minimizar os impactos resultantes das embalagens utilizadas através da sua integração no contexto da Política Nacional de Resíduos Sólidos (PNRS).

A PNRS foi instituída pela Lei 12.305/2010 (Brasil, 2010) buscando determinar a responsabilidade e seu compartilhamento correto na destinação dos resíduos e disposição adequada dos rejeitos. Um instrumento importante da PNRS que pode influenciar o segmento de águas minerais é a logística reversa, por meio da qual as empresas devem estabelecer formas de gerenciar o ciclo de vida do seu produto e a reutilização de embalagens de pós-consumo e pós-venda.

Nesse sentido, uma institucionalidade que precisa ser revista refere-se às normas estabelecidas pelo DNPM na Portaria 374/2009 que dispõe sobre as especificações técnicas para o aproveitamento da água mineral onde se afirma que as embalagens devem ser fabricadas com resinas virgens, tipo Policarbonato, PET ou similar. Esse fato interfere na reutilização dessas embalagens, no entanto, encontra-se em fase de implantação no mercado uma nova tecnologia que combina o insumo reciclado com a resina PET virgem tradicional, na proporção de $20 \%$ por $80 \%$, sendo que tal tecnologia já foi validada pela ANVISA (Accioli et al., 2011). Porém, essa nova tecnologia ainda é pouco utilizada pelas empresas do setor, o que demonstra a necessidade de torna-la mais efetiva, por meio de incentivos e uma maior institucionalidade para sua aplicação.

No que se refere à preservação do entorno da lavra e dos seus arredores, além da implantação dos parques hidrogeológicos e balneários, Canadá (2006), citando a lei 9.433/97 
da PNRH, afirma que é importante a incorporação das águas minerais na gestão dos recursos hídricos que, além do poder público, deve contar com a participação da comunidade e entidades civis para uma gestão descentralizada. Vale ressaltar que neste caso a própria participação de representantes de empresas de água mineral é de significativa importância, visto que um dos objetivos de um comitê de bacia hidrográfica é exatamente propor a criação de áreas de proteção dos recursos hídricos.

Considera-se também que uma parceria entre os órgãos públicos municipais e estas empresas deve levar a tomadas de decisão que beneficiem a comunidade local pela preservação ambiental. Tal fato poderá contribuir para uma maior fiscalização da exploração comercial das águas minerais, evitando assim os casos de captação acima da capacidade do aquífero e fomentando o uso sustentável do recurso.

\section{CONSIDERAÇÕES FINAIS}

O presente trabalho buscou caracterizar o segmento de águas minerais no Brasil, apontando elementos sobre sua estrutura e sobre sua dinâmica recente. Além disso, apresentou as formas institucionais desenhadas para o controle do acesso e dos recursos, explicitando os conflitos e desafios colocados à sua transformação, necessária para atender aos requisitos de uma boa governança para a sustentabilidade. Finalmente, foram apontados direcionamentos para o uso e exploração de maneira sustentável desse recurso, contribuindo para uma excelência na gestão ambiental nas empresas desse segmento.

A pesquisa realizada permitiu demonstrar que o mercado de águas minerais no Brasil é constituído por dois tipos principais de empresas, de um lado os grandes grupos empresariais nacionais e multinacionais; e do outro lado as pequenas empresas regionais. Porém, essas pequenas empresas estão sendo alvos de aquisição por parte dos grandes grupos, principalmente, multinacionais, o que aponta para uma possível concentração de capital nesse mercado. Esse fato ficou evidenciado com as recentes movimentações e aquisições realizadas pela Coca-Cola, pela Nestlé-Waters e pela Danone. Tal fato merece atenção por parte das instâncias institucionais brasileiras, pois, a concentração de um recurso tão importante em poucos agentes empresariais pode se tornar extremamente danoso às futuras gerações.

No entanto, o estudo também evidenciou os conflitos existentes entre diferentes instâncias, exatamente sobre essa questão institucional das águas minerais. Verificou-se que de um lado se encontram os agentes ligados diretamente à exploração comercial das águas minerais, representados principalmente por, DNPM, ABINAM e CNI que defendem a manutenção da atual institucionalidade baseada no Código de Mineração e no Código de Águas Minerais, contrários a uma integração das águas minerais com a gestão dos recursos hídricos. De outro lado encontram-se os órgãos de gestão de recursos hídricos, as entidades e ONGS ambientais e associações de moradores dos municípios com exploração comercial do recurso, que pedem o cumprimento da Constituição de 1988 e a referida integração das águas minerais na Política Nacional de Recursos Hídricos.

Posto isso, fundamenta-se como principal proposição das análises realizadas a necessidade de uma integração mais efetiva das águas minerais na gestão de recursos hídricos via PNRH, juntamente com a aplicação dos ditames da PNRS por meio da implantação do processo de logística reversa e melhor gestão do ciclo de vida do produto. Somam-se a esses direcionamentos a aplicação de instrumentos econômicos e de certificação que incentivem a adoção de padrões avançados de gestão ambiental por essas empresas.

Outro fato importante é o estabelecimento de um limite da participação dos grupos empresariais, sejam multinacionais ou nacionais, nesse segmento, impedindo assim que surjam grandes oligopólios concentrados na exploração de um recurso tão importante como a água, evitando ainda sua transformação em uma commodity. Salienta-se isso principalmente 
em vista da previsão para os próximos anos da continuidade da expansão no Brasil dos grupos multinacionais que dominam o mercado mundial: Coca-Cola, Danone, Nestlé e Pepsi.

A água seja ela superficial, subterrânea ou mineral, não deve ser vista como uma mercadoria ou commodity, mas como um recurso hídrico de domínio público e gerido pelas instituições da sociedade, visando não apenas ao objetivo econômico, mas também, social e ambiental. Essa consideração contribuiria fortemente para a gestão ambiental mais avançada por parte das empresas desse segmento.

\section{REFERENCIAS}

ACCIOLI, C.; MONTEIRO, S.; IAQUINTO, K. Reciclar é preciso. Conjuntura econômica, Rio de Janeiro, v. 65, n. 10, p. 18-37, out. 2011.

AGÊNCIA NACIONAL DE ÁGUAS - ANA (Brasil). Conjuntura dos recursos hídricos no Brasil: 2013. Brasília, 2013.

ARAÚJO, A. L. Um mar inteiro de lucro. 2009. IBRAM. Disponível em: http://www.ibram.org.br/150/15001002.asp?ttCD_CHAVE=82856. Acesso em: 10 mar. 2011.

BRASIL. Decreto-Lei 7.841/1945 de 8 de ago. 1945. Disponível em: http://www.dnpm.gov.br/conteudo.asp?IDSecao=67\&IDPagina=84\&IDLegislacao=3. Acesso em: 07 jan. 2012.

Decreto-Lei 227/1967 de 28 de fev. 1967. Disponível em: http://www.planalto.gov.br/ccivil_03/Decreto-Lei/Del0227.htm. Acesso em: 07 jan. 2012.

Constituição da República Federativa do Brasil. 1988. Brasília, DF: Senado, 1988.

Lei no 9.433 de 8 de jan. 1997. Institui a Política Nacional de Recursos Hídricos, cria o Sistema Nacional de Gerenciamento de Recursos Hídricos, regulamenta o inciso XIX do art. 21 da Constituição Federal, e altera o art. $1^{\circ}$ da Lei $n^{\circ} 8.001$, de 13 de março de 1990, que modificou a Lei $\mathrm{n}^{\circ}$ 7.990, de 28 de dezembro de 1989. Disponível em: http://www.planalto.gov.br/ccivil_03/leis/L9433.htm. Acesso em: 15 dez. 2011.

Decreto 6.101 - 26 de abr. 2007. Aprova a Estrutura Regimental e o Quadro Demonstrativo dos Cargos em Comissão e das Funções Gratificadas do Ministério do Meio Ambiente, e dá outras providências. Disponível em: http://www.planalto.gov.br/ccivil_03/_Ato2007-2010/2007/Decreto/D6101.htm. Acesso em: 07 out. 2011.

Resolução $\mathbf{n}^{0} 76$ de 16 de out. 2007. Estabelece diretrizes gerais para a integração entre a gestão de recursos hídricos e a gestão de águas minerais, termais, gasosas, potáveis de mesa ou destinadas a fins balneários. Disponível em: http://www.cnrh.gov.br/sitio/index.php?option=com_docman...17. Acesso em: 07 jan. 2012.

Lei $\mathbf{n}^{\mathbf{0}} 12.305$ de 2 de ago. 2010. Institui a Política Nacional de Resíduos Sólidos; altera a Lei $\mathrm{n}^{\circ}$ 9.605, de 12 de fevereiro de 1998; e dá outras providências. Disponível em: http://www.planalto.gov.br/ccivil03/ato2007-2010/2010/lei/112305.htm. Acesso em: 15 set. 2011.

BRASIL. Ministério de Minas e Energia. Relatório Técnico 57 - Perfil da água mineral. Brasília: SGM; BIRD, 2009. 
CAETANO, L. C. A política da água mineral: uma proposta de integração para o Estado do Rio de Janeiro. 2005. 299 f. Tese (Doutorado em Ciências) - Instituto de Geociências da Unicamp, Campinas, 2005.

CANADA, C. B. dos S. A política de água mineral e a avaliação do indicador energéticoambiental: uma proposta de política pública para o município de Poá - SP. 2006. $94 \mathrm{f}$. Dissertação (Mestrado em Engenharia Civil). Faculdade de Engenharia Civil, Arquitetura e Urbanismo da Unicamp, Campinas, 2006.

COMPANHIA DE PESQUISA DE RECURSOS MINERAIS. Serviço Geológico do Brasil. A evolução da produção de água mineral no Brasil. 2011. Disponível em: http://www.cprm.gov.br/publique/cgi/cgilua.exe/sys/start.htm?infoid=1386\&sid=46. Acesso em: 11 jan. 2012.

DEPARTAMENTO NACIONAL DE PRODUÇÃO MINERAL - DNPM (Brasil). Anuário Mineral Brasileiro 2006. Brasília: Ministério de Minas e Energia, 2006.

Anuário Mineral Brasileiro 2007. Brasília: Ministério de Minas e Energia, 2007.

Anuário Mineral Brasileiro 2010. Brasília: Ministério de Minas e Energia, 2010.

Portaria 374/2009: aprova a norma técnica que dispõe sobre as especificações técnicas para o aproveitamento da água mineral, termal, gasosa e potável de mesa. Disponível em:

http://www.dnpm.gov.br/conteudo.asp?IDSecao=67\&IDPagina=84\&IDLegislacao=575 Acesso em: 10 jan. 2012.

GUIMARAES, B. C. A importância da água mineral. Revista das águas, São Paulo, ano 2, n. 6, jun. 2008.

KULAIF, Y. Sumário mineral: água mineral. São Paulo: DNPM, 2010.

MENDES, J. T. G. Economia: fundamentos e aplicações. São Paulo: Pearson, 2005.

NAÇÕES UNIDAS. Water scarcity. Disponível em:

<http://www.un.org/waterforlifedecade/scarcity.shtml>. Acesso em: 19 jun. 2014.

NINIS, A. B. A ecologia política e a exploração da água mineral de São Lourenço. 2006. 187 f. Dissertação (Mestrado em Desenvolvimento Sustentável) - Centro de Desenvolvimento Sustentável da Universidade de Brasília, Brasília, 2006.

OBATA, O. R.; CABRAL JÚNIOR, M.; SINTONI, A. Águas minerais orientação para regularização e implantação de empreendimentos. São Paulo: Instituto de Pesquisas Tecnológicas, 2005.

ROSA, F. V. T. da. Elementos para estudo de viabilidade de projetos de explotação de água mineral. 1999. 138f. Dissertação (Mestrado em Administração e Política de Recursos Minerais) - Instituto de Geociências da Unicamp, Campinas, 1999.

TACHIZAWA, T. Gestão ambiental e responsabilidade social corporativa. 3. ed. São Paulo: Atlas, 2005. 